\title{
Finite Element Analysis to Predict Temperature Rise Tests in High-Capacity Substation Connectors
}

\begin{tabular}{|r|l|}
\hline Journal: & IET Generation, Transmission \& Distribution \\
\hline Manuscript ID & GTD-2016-1717.R1 \\
\hline Manuscript Type: & Research Paper \\
\hline Complete List of Authors: & $\begin{array}{l}\text { Capelli, Francesca; Universitat Politècnica de Catalunya, Electrical } \\
\text { Engineering } \\
\text { Riba, Jordi-Roger; Univ Politecn Cataluna, Electrical Engineering } \\
\text { Sanllehí, Josep; SBI-Connectors España }\end{array}$ \\
\hline Keyword: & $\begin{array}{l}\text { CONDUCTORS (ELECTRIC), HEAT TRANSFER, FINITE ELEMENT ANALYSIS, } \\
\text { SIMULATION }\end{array}$ \\
\hline
\end{tabular}

\section{SCHOLARONE ${ }^{\text {M }}$ \\ Manuscripts}




\title{
Finite Element Analysis to Predict Temperature Rise Tests in High- Capacity Substation Connectors
}

\author{
F. Capelli ${ }^{1}$, J.-R. Riba $^{1 *}$, and J. Sanllehí ${ }^{2}$ \\ ${ }^{1}$ Electrical Engineering Department, Universitat Politècnica de Catalunya, 08222 Terrassa, \\ Spain \\ ${ }^{2}$ SBI-Connectors Spain SAU, 08635 Sant Esteve Sesrovires, Spain \\ ${ }^{*}$ Corresponding author: riba@ee.upc.edu
}

\begin{abstract}
In the last years there has been a considerable increase in electricity consumption and generation from renewable sources, especially wind and solar photovoltaic. This phenomenon has increased the risk of line saturation with the consequent need of increasing the capacity of some power lines. Considering the high cost and the time involved in installing new power lines, the difficulty in acquiring tower sites and the related environmental impacts, some countries are considering to replace conventional conductors with HTLS (High-Temperature Low-Sag) conductors. This is a feasible and economical solution. In this paper a numerical-FEM (Finite Element Method) approach to simulate the temperature rise test in both conventional and high-capacity substation connectors compatible with HTLS technology is presented. The proposed coupled electric-thermal 3D-FEM transient analysis allows calculating the temperature distribution in both the connector and the conductors for a given current profile. The temperature distribution in conductors and connectors for both transient and steady state conditions provided by the proposed simulation method shows good agreement with experimental data.
\end{abstract}

\section{Introduction}

In the last years there has been a considerable increase in electricity consumption, particularly in developing countries. Forecasts indicate that this trend will continue in the coming years. According to the International Energy Agency (IEA), in the next years there will be an increase in world energy consumption and a very important part of the generation (around 50\%) will come from renewable energy sources. It is also estimated that in 10 years electricity consumption from renewable sources will increase about $25 \%$ in many European countries [1]. This increase in power consumption has caused the risk of line saturation in some areas and the consequent need to increase power lines capacity. However, it is often extremely difficult to build new distribution and transmission lines, especially in urban areas or in regions of ecological interest [2].

Considering the high cost of installing new power lines, the difficulty in acquiring tower sites and the related environmental impacts, social concerns, and the time involved in building new lines, a solution that some countries have chosen due to its technological and economic feasibility, is the replacement of conventional conductors with others operating at high temperature, known as HTLS conductors (HighTemperature Low-Sag). These conductors, with a similar section than the conventional ones, allow increasing the nominal current capacity, with a consequent increase in operating temperature. HTLS conductors can operate continuously (in steady-state conditions) at temperatures from 150 to $250^{\circ} \mathrm{C}$, and 
allow, in many cases, doubling the capacity of existing lines [3]. The definition of an electric connector, according to the ANSI/NEMA CC 1-2009 standard [4] is "a device that joins two or more conductors for the purpose of providing a continuous electrical path". Therefore, substation electrical connectors, the joints that physically connect power transmission lines with substation conductors and bus bars, play a critical role in the efficiency and reliability of transmission systems and power distribution. It is recognized that a failure in a single connector can cause the failure of the entire line. For this reason electrical connectors can be regarded among the weaker elements in electric transmission lines [5] and therefore their reliability must be ensured.

This paper deals with high-capacity substation connectors compatible with HTLS technology. The new families of high-capacity substation connectors compatible with HTLS technology have to be designed to withstand, under rated operating conditions, temperatures higher than the traditional application, to prevent failures that could have serious consequences on the power transmission system. Therefore, service temperature is a key design variable in high-capacity substation connectors. Moreover, before their installation, substation connectors have to be tested in accordance to the international standards. The ANSI/NEMA CC1-2009 standard [4] describes the procedures to carry out standardized temperature rise tests. The temperature rise test allows determining the substation connector's thermal behavior under both transient and steady state conditions and thus evaluating if its size and design is compatible with the electromagnetic-thermal stress at which it is subjected during normal operational conditions. According to the ANSI/NEMA CC1-2009, the temperature rise must be performed at $100 \%$, $125 \%$, and $150 \%$ of the rated current, until attaining the equilibrium temperatures at each current level. The standard describes the equilibrium temperature as a constant temperature with $+/-2^{\circ} \mathrm{C}$ accuracy among three successive temperature measurements taken every five minutes. The rated current considered for this test must be obtained from tabulated values which establish the testing current as a function of the conductor size. The ANSI/NEMA CC1-2009 standard requires that under rated current conditions, the temperature of the tested connector does not exceed the temperature of reference conductors [4].

Temperature rise tests usually last a long time, are very power-consuming and therefore expensive. Thus, the development of a realistic simulation tool is essential for anticipating the results of the mandatory laboratory temperature rise tests in a fast way, which is especially useful during the design and optimization phases of substation connectors [6]. Generally, the temperature rise in power devices is primarily resulting from Joule's losses due to the electrical current. During the last years different authors have developed coupled electric and thermal models to evaluate the temperature rise in power devices, including bus bars, power conductors and cables [7-14], although most of the references are based on 1D 
or $2 \mathrm{D}$ formulations or do not take into account radiative cooling effects. A realistic transient $3 \mathrm{D}$ simulation method for predicting the temperature rise in complex-shaped electrical connectors has not been studied and developed yet.

In this paper a numerical method based on FEM simulations is presented to model the temperature rise in high-capacity substation connectors, although this approach is also useful to simulate the temperature rise of other types of connectors and power devices. The proposed coupled electric-thermal 3D-FEM transient analysis allows calculating the temperature distribution in both the connector and the conductors for a given test current profile. It is worth noting that the heat transfer coefficients to determine the temperature distribution in the analyzed domain are calculated as a function of the geometry, fluid properties and surface temperatures using dimensional analysis. The results are validated by means of experimental data.

\section{The 3D-FEM method}

Three-dimensional finite element modelling (3D-FEM) is a powerful and versatile tool that allows simulating the temperature distribution in complex shaped three-dimensional objects such as power connectors, providing accurate solutions when applying a suitable approach $[15,16]$.

The modeling method applied in this paper is based on coupled electric-thermal physics. Power losses calculated in the electric field analysis are used as the input data for the thermal analysis to predict the temperature rise in the analyzed geometry. The wide range of substation connectors' geometries and the need to solve coupled electric and thermal equations requires suitable calculation tools. The $\mathrm{COMSOL}^{\circledR}$ commercial FEM package [17], has been used in this paper.

Complete 3D-FEM simulations together with the computation of the partial differential equations required to analyze in detail the studied phenomenon may become highly time-demanding due to their computational burden when increasing the number of elements and equations to be solved simultaneously. Thus, the 3D geometric models dealt with have been prepared and simplified with the aim to reduce its complexity. The 3-D mesh applied to the analyzed geometries is composed of 3-D tetrahedral elements. The mesh of Model I consists of 466,561 domain elements, 105,594 boundary elements, and 19,525 edge elements, whereas the mesh of Model II consists of 197,778 domain elements, 40,543 boundary elements, and 6,603 edge elements. Figs. 1 show the meshes of the analyzed domains for Models I and II, respectively. 

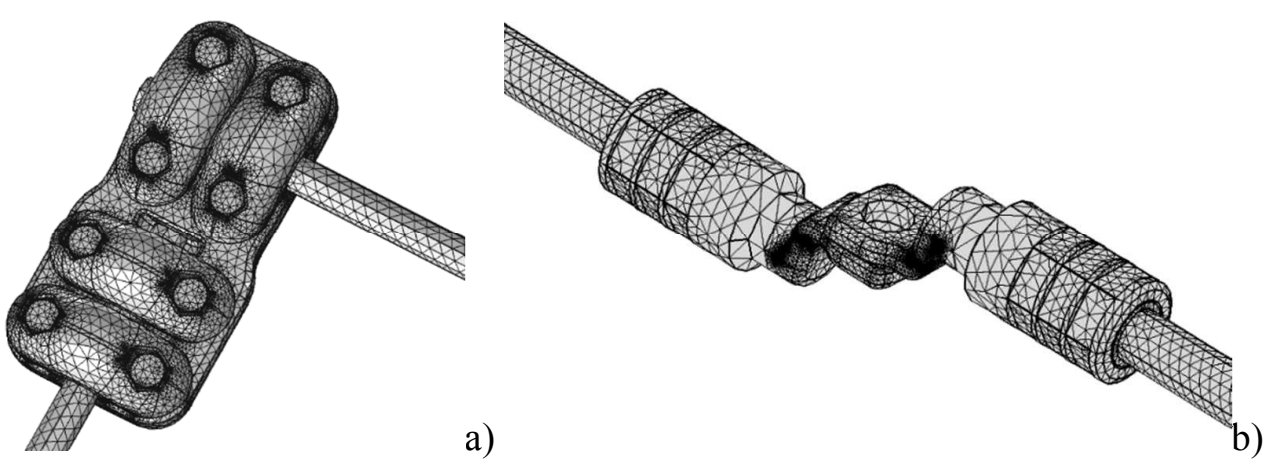

Fig.1. a) Model I. Mesh of the analyzed S210ZTLS high-capacity substation connector. b) Model II used to validate the simulation system proposed in this paper. Mesh of the analyzed ICAUL185 low-voltage bimetallic terminal connector.

\subsection{Electric analysis}

Power losses per unit volume in $\mathrm{W} \cdot \mathrm{m}^{-3}$ are calculated as the dot product between the current density $\vec{J}$ in $\mathrm{Am}^{-2}$, and the electric field $\vec{E}$ in $\mathrm{Vm}^{-1}$,

$$
P_{j h}=\vec{J} \cdot \vec{E}
$$

$P_{j h}$ being the internal heat source considered in the 3D differential heat transfer equation detailed in Section 2.2. Therefore this is the link between the electric and thermal analysis of the multi-physic problem dealt with.

The electric field $\vec{E}$ is determined by the gradient of the electric potential,

$$
\vec{E}=-\vec{\nabla} \mathrm{V}
$$

where $\vec{\nabla}=\left(\frac{\partial}{\partial x}, \frac{\partial}{\partial y}, \frac{\partial}{\partial z}\right)$.

The time-harmonic charge continuity equation has also been considered to solve the problem,

$\vec{\nabla} \cdot \vec{J}=-\frac{\partial \rho_{e}}{\partial t}=-j \omega \rho_{e}$

$\rho_{e}$ being the electrical charge per unit volume and $\omega$ the angular frequency.

By substituting the Ohm's law $\vec{J}_{c}=\sigma_{e} \vec{E}$ ( $\sigma_{e}$ being the electrical conductivity in S/m) that relates the conduction current density with the electric field and the Gauss law $\vec{\nabla} \cdot \vec{E}=\rho_{e} / \varepsilon$ ( $\varepsilon$ being the material's permittivity) in (3) and taking (2) into account, it results the equation to be solved in all points of the considered domain,

$$
\vec{\nabla}\left(-\sigma_{e} \cdot \vec{\nabla} \mathrm{V}\right)=-j \omega \varepsilon \vec{\nabla} \cdot(-\vec{\nabla} V)
$$

where (4) can be written in a more convenient form as,

$$
\vec{\nabla}\left(\left(\sigma_{e}+j \omega \varepsilon\right) \cdot \vec{\nabla} V\right)=0
$$

It is noted that the electrical conductivity is assumed to be temperature dependent [18] [19], 
$\sigma_{e}=\frac{1}{\rho_{e, 0}\left[1+\alpha_{e}\left(T-T_{o}\right)\right]}$

$T$ being the temperature, $\rho_{e, 0}$ the resistivity at the reference temperature $\left(T_{0}=293.15 \mathrm{~K}\right)$ and $\alpha_{e}$ the temperature coefficient. The electrical conductivity is automatically updated at each simulation step in each node of the domain.

The main electric and magnetic parameters used in the 3D-FEM simulations are shown in Table 1.

Table 1 Main Electric and Magnetic Parameters

\begin{tabular}{llll} 
Parameter & Symbol & Units & Value \\
\hline Free-space permittivity & $\varepsilon_{0}$ & $\mathrm{~F} \mathrm{~m}^{-1}$ & $8.85 \times 10^{-12}$ \\
Aluminum relative permittivity & $\varepsilon_{r, A l}$ & - & 1 \\
A356 alloy relative permittivity & $\varepsilon_{r, A 356}$ & - & 1 \\
Steel relative permittivity & $\varepsilon_{r, F e}$ & - & 1 \\
Copper relative permittivity & $\varepsilon_{r, C u}$ & - & 1 \\
Air relative permittivity & $\varepsilon_{r, a i r}$ & - & 1 \\
Aluminum reference resistivity & $\rho_{A l}$ & $\Omega \mathrm{m}$ & $2.77 \times 10^{-8}$ \\
A356 alloy reference resistivity & $\rho_{A 356}$ & $\Omega \mathrm{m}$ & $4.44 \times 10^{-8}$ \\
Steel core reference resistivity & $\rho_{F e}$ & $\Omega \mathrm{m}$ & $7.96 \times 10^{-6}$ \\
Steel bolts reference resistivity & $\rho_{B o}$ & $\Omega \mathrm{m}$ & $6.90 \times 10^{-7}$ \\
Copper reference resistivity & $\rho_{C u}$ & $\Omega \mathrm{m}$ & $1.68 \cdot 10^{-8}$ \\
Aluminum temp. coefficient & $\alpha_{A l}$ & $\mathrm{~K}^{-1}$ & 0.0041 \\
A356 alloy temp. coefficient & $\alpha_{A 356}$ & $\mathrm{~K}^{-1}$ & 0.004 \\
Steel core temp. coefficient & $\alpha_{F e}$ & $\mathrm{~K}^{-1}$ & 0.0041 \\
Copper temp. coefficient & $\alpha_{C u}$ & $\mathrm{~K}^{-1}$ & 0.0039 \\
Contact resistance factor (substation connector) ${ }^{1}$ & - & - & 2 \\
Contact resistance factor (bimetallic connector) & - & - & 0.5 \\
\hline Ratio betwen the contact resistance and the butk & - & & \\
\hline & & & \\
\hline
\end{tabular}

${ }^{\mathrm{I}}$ Ratio between the contact resistance and the bulk resistance of the connector [20]

\subsection{Thermal analysis}

The conduction heat transfer equation is expressed as follows [21]:

$$
\rho C_{P} \frac{\partial T}{\partial t}=-\vec{\nabla} \cdot \vec{q}+\vec{J} \cdot \vec{E}
$$

where $\rho$ is the volumetric mass density in $\mathrm{kg} \cdot \mathrm{m}^{-3}, C_{p}$ the specific heat capacity in $\mathrm{J} \cdot \mathrm{kg}^{-1} \mathrm{~K}^{-1}$ and $\vec{q}$ the heat flux density in $\mathrm{W} \cdot \mathrm{m}^{-2}$, whereas the last term $\vec{J} \cdot \vec{E}$ is the heat source in $\mathrm{W} / \mathrm{m}^{3}$, i.e. the specific power generated by the Joule effect, as specified in (1). 
By taking into account the temperature dependence of resistivity as in (6), the conduction heat transfer equation can be expressed as,

$$
\rho C_{P} \frac{\partial T}{\partial t}=k \nabla^{2} T+\rho_{e, 0}\left[1+\alpha_{e}\left(T-T_{o}\right)\right] \vec{J} \cdot \vec{J}
$$

Simulations carried out consider the volumetric mass density, specific heat capacity and thermal conductivity of aluminum, A356 alloy, steel and copper as constant parameters. The materials are considered isotropic.

It is assumed that the object under test has been assembled and then acclimated to the temperature of the indoor test area until reaching a stable and homogeneous temperature. Formally, the initial condition for thermal problem can be expressed as,

$$
T(x, y, z, 0)=T_{\text {room, }} \text { before test }
$$

$T(x, y, z, t)$ being the temperature distribution at any point $(x, y, z)$ in the analyzed domain at a time $t$.

The flux boundary condition, to which (8) is subjected, includes natural convection and radiation with the external ambient. It is defined on the outer surface $S$ and can be expressed as follows [22],

$$
-\vec{n} \cdot(-k \vec{\nabla} T)=h\left(T_{\infty}-T\right)+\varepsilon \sigma\left(T_{\infty}{ }^{4}-T^{4}\right)
$$

where $\vec{n}$ is a unit vector normal to the boundary $S$ pointing outward from the considered domain $\Omega, h$ is the convective coefficient in $\mathrm{Wm}^{-2} \mathrm{~K}^{-1}, T_{\infty}$ is air temperature in $\mathrm{K}, T$ is the surface temperature in $\mathrm{K}, \varepsilon$ is the dimensionless emissivity coefficient and $\sigma$ is the Stefan-Boltzmann constant. Surface-to-ambient radiation is calculated based on the assumption that the ambient behaves as a black body at temperature $T_{\infty}$.

The main thermal parameters used in the 3D-FEM simulations are listed in Table 2.

Table 2 Main Thermal Parameters

\begin{tabular}{llll}
\hline Parameter & Symbol & Units & Value \\
\hline Aluminum density & $\rho_{A l}$ & $\mathrm{~kg} \mathrm{~m}^{-3}$ & 2700 \\
A356.0 alloy density & $\rho_{A 356}$ & $\mathrm{~kg} \mathrm{~m}^{-3}$ & 2685 \\
Steel density & $\rho_{F e}$ & $\mathrm{~kg} \mathrm{~m}^{-3}$ & 7850 \\
Copper density & $\rho_{C u}$ & $\mathrm{~kg} \mathrm{~m}^{-3}$ & 8700 \\
Aluminum specific heat capacity & $C_{p, A l}$ & $\mathrm{~J} \mathrm{~kg} \mathrm{~K}^{-1}$ & 900 \\
A356.0 alloy specific heat capacity & $C_{p, A 356}$ & $\mathrm{~J} \mathrm{~kg}^{-1} \mathrm{~K}^{-1}$ & 900 \\
Steel specific heat capacity & $C_{p, F e}$ & $\mathrm{~J} \mathrm{~kg}^{-1} \mathrm{~K}^{-1}$ & 475 \\
Copper specific heat capacity & $C_{p, C u}$ & $\mathrm{~J} \mathrm{~kg}^{-1} \mathrm{~K}^{-1}$ & 385 \\
Aluminum thermal conductivity & $k_{A l}$ & $\mathrm{~W} \mathrm{~m}^{-1} \mathrm{~K}^{-1}$ & 160 \\
A356 alloy thermal conductivity & $k_{A 356}$ & $\mathrm{~W} \mathrm{~m}^{-1} \mathrm{~K}^{-1}$ & 151 \\
Steel thermal conductivity & $k_{F e}$ & $\mathrm{~W} \mathrm{~m}^{-1} \mathrm{~K}^{-1}$ & 44.5 \\
Copper thermal conductivity & $k_{C u}$ & $\mathrm{~W} \mathrm{~m}^{-1} \mathrm{~K}^{-1}$ & 400 \\
Stefan-Boltzmann constant & $\sigma$ & $\mathrm{W} \mathrm{m}^{-2} \mathrm{~K}^{-4}$ & $5.670373 \times 10^{-8}$ \\
\hline
\end{tabular}




\subsection{Heat transfer coefficients}

Convection is usually classified into two types, that is, natural and forced convection. Natural convection has low cooling effect compared to forced convection [23]. According to the ANSI/NEMA CC1-2009 standard [4], the temperature rise test on substation connectors can be conducted indoors or outdoors, at the discretion of the manufacturers. In this paper indoor tests are considered since they are more applied, where cooling contribution is only due to natural convection and thermal radiation, thus representing the most conservative testing conditions.

Since convection phenomena are very complex and depend on many variables including surface shape and dimensions, flow regime, fluid temperature and different properties (kinematic viscosity, density, thermal conductivity, specific heat) among others [24], heat transfer by convection is usually treated empirically. The most common approach to convective cooling is from experimental studies supported by dimensional analysis [25].

In the technical literature there are available several heat transfer correlations for isothermal surfaces of the most basic geometries [26, 27]. Since conductors' and connector's surfaces are not isothermal, this paper assumes that heat transfer correlations change with temperature and are recalculated at each simulation step.

The Nusselt number defined by Churchill and Chu's correlation [28] has been used in the conductors' surfaces and cylindrical parts of the connectors, which have been modelled as horizontal cylinders,

$$
N u_{L c}=\left\{0.60+\frac{0.387 R a_{L c}^{1 / 6}}{\left[1+\left(\frac{0.559}{P r}\right)^{9 / 16}\right]^{8 / 27}}\right\}^{2}
$$

$R a_{L c}$ being the Rayleigh number, with $10^{-5}<R a_{L c}<10^{12}$.

It is worth noting that the Rayleigh number is defined for a characteristic length $L_{c}$ in $\mathrm{m}$. In the case of the conductors' and barrel's surfaces it corresponds to the cylinder's diameter, whereas for the connector's surface it has been calculated as the ratio between the surface area and the perimeter [29].

The Nusselt numbers proposed by McAdams [29] have been implemented for the remaining connector's surfaces, which are modelled as flat surfaces, with upward and downward cooling. Therefore, for the upper part of the connectors (the caps in Model I, and palms' upper surfaces in Model II), the Nusselt number for upward cooling has been calculated as,

$$
\begin{aligned}
& N u_{L c}=0.54 R a_{L c}^{1 / 4} \\
& \text { with } 10^{4}<R a_{L c}<10^{7} .
\end{aligned}
$$


For the bottom parts of the connectors (connector's body in Model I and copper palm's lower surfaces in Model II), the Nusselt number for downward cooling has been calculated as,

$N u_{L C}=0.27 R a_{L c}{ }^{1 / 4}$

with $10^{5}<R a_{L C}<10^{10}$.

The Rayleigh number is calculated as the product of Grashof and Prandtl numbers,

$R a_{L C}=G r_{L C} \cdot P r$

The Grashof number is calculated as,

$G r_{L c}=\frac{g \beta \rho^{2}\left(T_{w}-T_{\infty}\right) L c^{3}}{\mu^{2}}$

and the Prandtl number is,

$\operatorname{Pr}=\frac{C_{p} \mu}{k}$

where $g$ is the acceleration due to Earth's gravity expressed in $\mathrm{m} \cdot \mathrm{s}^{-2}, \beta$ the thermal expansion coefficient in $\mathrm{K}^{-1}$ (whose value is $1 / T$ for ideal gases, $T$ being the absolute temperature), $\rho$ the fluid volumetric mass density in $\mathrm{kg} \cdot \mathrm{m}^{-3}, T_{w}$ the surface temperature in $\mathrm{K}, T_{\infty}$ the quiescent temperature (fluid temperature far from the surface of the object) in $\mathrm{K}, \mu$ the fluid dynamic viscosity in $\mathrm{Pa} \cdot \mathrm{s}, C_{p}$ the fluid specific heat in $\mathrm{J} \cdot \mathrm{kg}^{-1} \cdot \mathrm{K}^{-1}$ and $k$ the thermal conductivity in $\mathrm{W} \cdot \mathrm{m}^{-1} \cdot \mathrm{K}^{-1}$.

The Nusselt number represents the ratio between the heat that is exchanged by convection between the surface and the fluid, and the heat that would exchange the same surface by conduction through a layer of fluid of thickness $L_{c}$ with zero velocity [24,30]. Higher values of the Nusselt number indicate a greater influence of the mass transport in heat exchange. Thus, $N u_{L c}$ is related to the convective coefficient as follows,

$h=\frac{N u_{L c} \cdot k}{L c}$

Fluid properties (air density $\rho$, viscosity $\mu$, and thermal conductivity $k$ ) are temperature dependent, thus they have been taken from tabulated values [23] as a function of the air film temperature $T_{\text {film }}$ and updated at each simulation step.

$T_{\text {film }}=\frac{T_{\infty}+T_{w}}{2}$

Regarding the radiative heat exchange, the basic objective is to estimate the heat radiant energy emitted by the surfaces. Taylor and House [31] conducted studies to obtain experimental data of the surface heat emissivity of aluminum conductors with varying surface conditions. They concluded that the emissivity can increase from about 0.2 to about 0.9 with conductor's age. The exact rate of increase is difficult to determine due to the different variables that affect the aging rate. When conductor's surface 
conditions are unknown, the IEEE Std. 738-2006 [23] suggests dealing with emissivity values of 0.5. This value has been used in this paper for AAAC conductors, whose emissivity was unknown, whereas for ACSS conductors, the data-sheet value of 0.45 was applied, since it was provided by the manufacturer [32].

Emissivity measurements for many surfaces are compiled in different technical references [33-35]. Connectors' surface emissivity values that have been considered in this analysis are summarized in Table 3.

Table 3 Emissivity values used in 3D-FEM simulation

\begin{tabular}{rll}
\hline Part & & Emissivity \\
\hline 1. & ACSR conductors & 0.45 \\
2. & AAAC conductors; & 0.50 \\
3. & Connectors' surfaces [35] & 0.46 \\
4. & Steel bolts [35] & 0.35
\end{tabular}

\section{The analyzed connectors}

The main object of this paper is a high-capacity substation T-connector prototype from SBIConnectors, which is shown in Fig. 2a (Model I). It connects two ACSS (Aluminum Conductor Steel Supported) LARK conductors of $20.5 \mathrm{~mm}$ diameter each. The connector is made of A356.0 cast aluminum alloy with T6 heat treatment.

With the aim to validate the model, the same simulation method has been applied to a low-voltage bimetallic terminal connector ICAUL185 which connects an AAAC (All Aluminum Alloy Conductor) of $16.5 \mathrm{~mm}$ diameter to a terminal (Model II). The connector, shown in Fig. 2b is composed of Al $99.5 \%$ (barrel), and $\mathrm{Cu} 99.9 \%$ (palm).
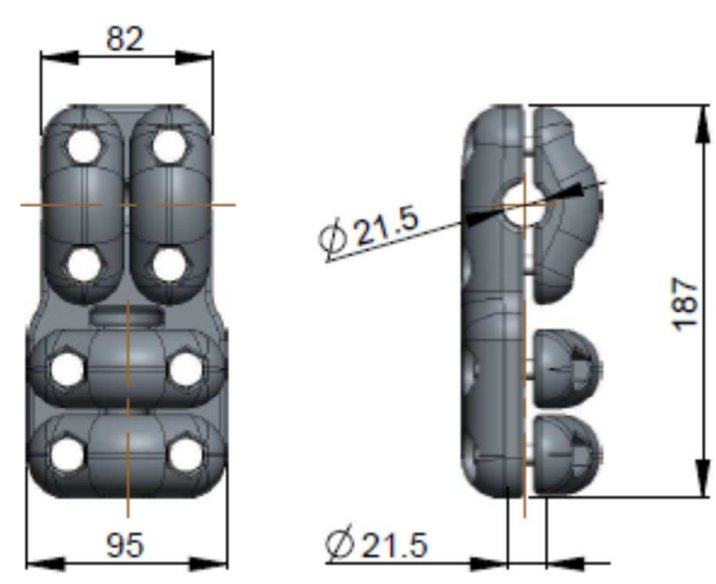

a)

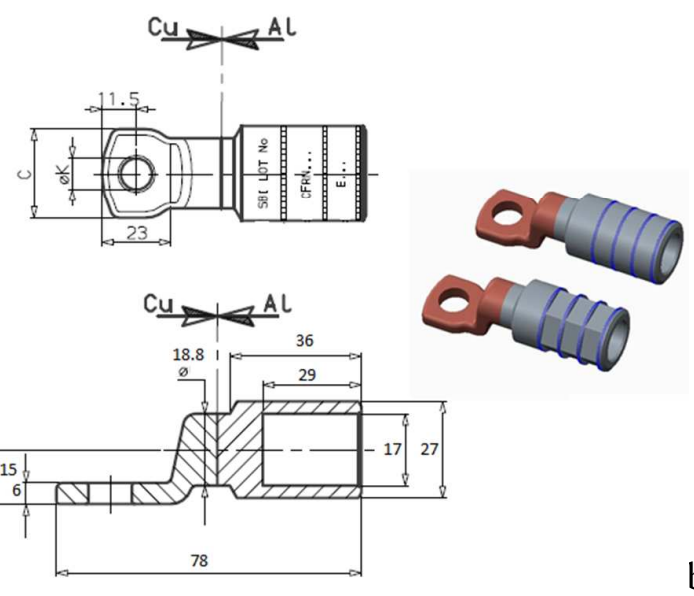

b)

Fig. 2. a) 2-D plot of the analyzed substation T-connector (Model I). b) 2-D plot of the analyzed bimetallic connector (Model II). 
Table 4 summarizes the main characteristics of the analyzed connectors.

Table 4 The analyzed connectors

\begin{tabular}{lllll}
\hline Model & Connector & Conductor & Parts & Material \\
\hline Model I & Substation T- & ACSS LARK & ACSS Conductor & Aluminum/Steel \\
& Connector & $\mathrm{d}=20.5 \mathrm{~mm}$ & T-connector & A356.0 alloy \\
& & & Bolts & Steel \\
\multirow{2}{*}{ Model II } & Bimetallic & \multirow{2}{*}{ AAAC d $=16.5 \mathrm{~mm}$} & ACCC Conductor & Aluminum \\
& Connector & & Connector's Barrel & Aluminum $99.5 \%$ \\
& & & Connector's Palm & Copper $99.9 \%$ \\
\hline
\end{tabular}

\section{Experimental setup}

\subsection{Experimental setup to test Model I connectors}

Whit the aim to verify the simulation results, a temperature rise test according to the requirements of the NEMA CC1-2009 [4] was conducted in the AMBER-UPC laboratory, with Model I connectors. The test object was a closed loop circuit of three connectors, as shown in Fig. 3. The loop was composed of a S210ZTLST-connector, two S210ZA4P23LS terminal connectors and an ACSS LARK conductor with diameter $d=20.5 \mathrm{~mm}$. A torque of $35 \mathrm{~N} \cdot \mathrm{m}$ was applied to the M10 bolts of the connectors by means of a calibrated torque wrench, which allows maintaining the connection integrity and ensuring an adequate contact resistance.
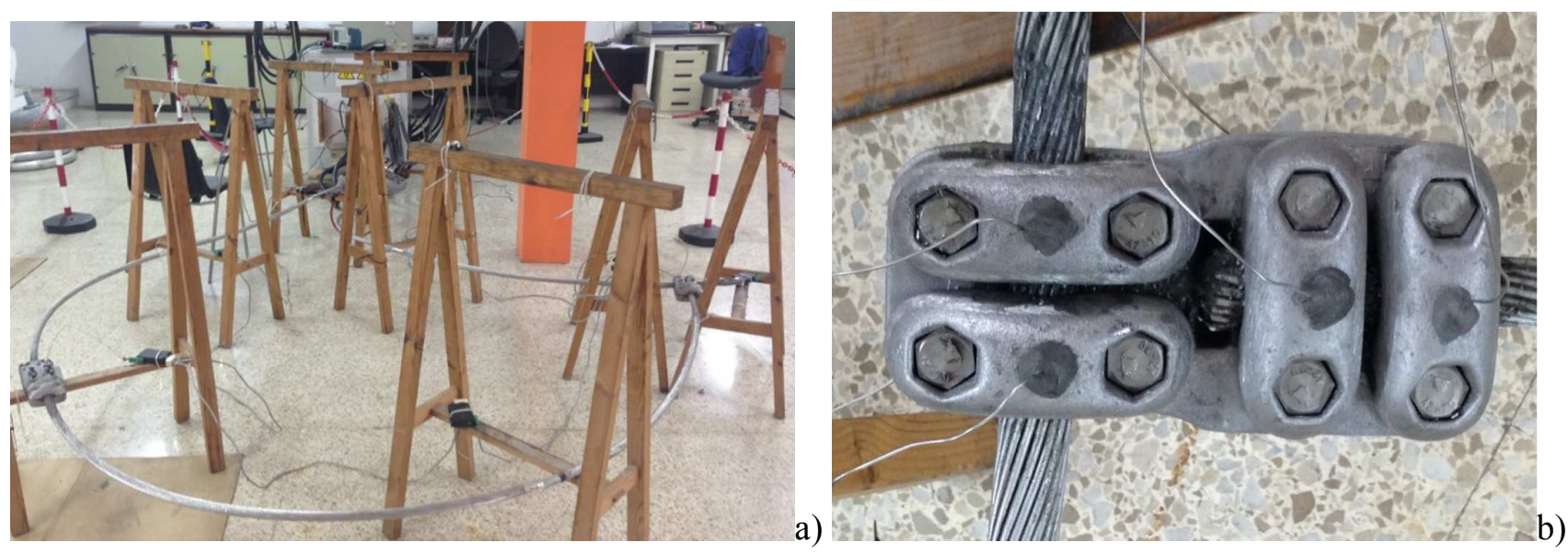

Fig. 3. Experimental test setup. a) Test loop composed of an ACSS conductor, a T-connector S210ZTLS and two terminal connectors S210ZA4P23LS. b) T-connector S210ZTLS. The five thermocouples placed in the different parts of the connector. 
Experimental tests were performed at atmospheric conditions $\left(28^{\circ} \mathrm{C}, 982.7 \mathrm{hPa}\right.$ and $52.3 \%$ relative humidity). The experimental setup to conduct the temperature rise test consisted of a single-phase variable autotransformer connected in series with a single-phase transformer (120 kVA, 0-10 kA, $50 \mathrm{~Hz})$. They were connected to the outer loop, which included the connectors described above. A calibrated Rogowski coil probe (Fluke i6000s Flex) was used to measure the output current provided by the transformer. Current measurements have an uncertainty of about $2 \%$.

To measure the temperature in steady state condition, $16 \mathrm{~K}$-type thermocouples with an AISI 316 external sheath of $1 \mathrm{~mm}$ diameter were placed on the connectors' bodies and on the top points of each conductor. When necessary, a small hole was drilled through the connector body, to ensure the correct placement of the thermocouple. Another K-type thermocouple was used to measure the room temperature. The thermocouples were connected to an acquisition card and the signal was processed by a PC. Measures were acquired every 10 seconds.

\subsection{Model II: Experimental setup to test Model II connectors}

With the aim to verify the proposed simulation method, a thermal cycling test according to the requirements of the ANSI C119.4 standard [36] was conducted in AMBER-UPC laboratory, using Model II connectors.

The test object was a closed loop of five pairs of terminal connectors, joined by means of a steel bolt, as shown in Fig 4. The loop was composed of ten ICAUL185 terminals and an AAAC conductor with diameter $d=16.5 \mathrm{~mm}$.
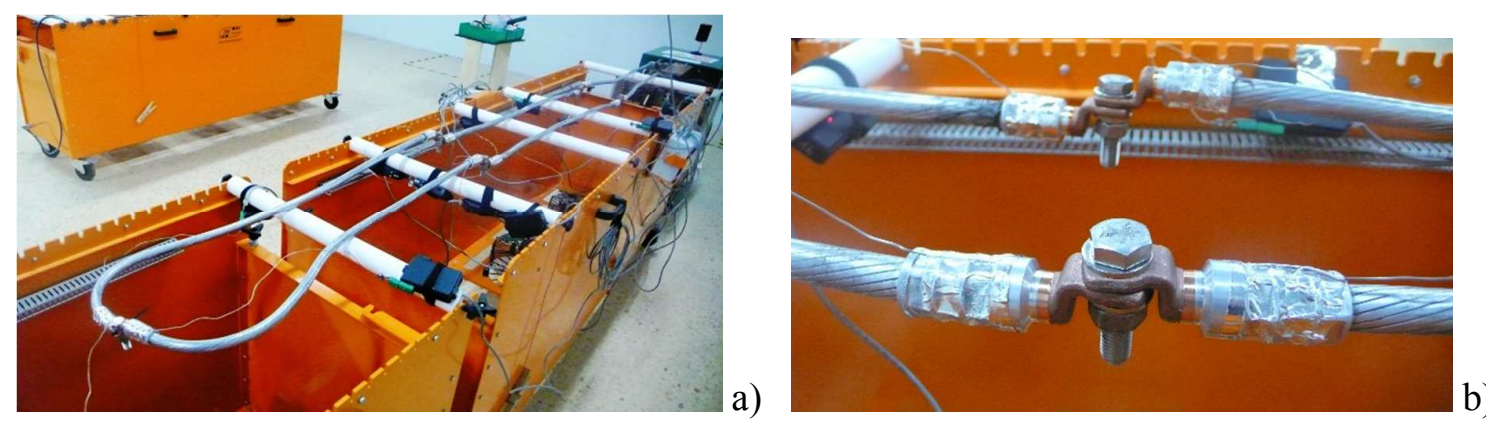

Fig. 4. a) Experimental setup. Tested loop composed of an AAAC conductor and twelve bimetallic connectors ICAUL185. b) Bimetallic connector ICAU185. Thermocouples are placed at the barrel's surface.

The tests were performed at atmospheric conditions $\left(20^{\circ} \mathrm{C}\right)$. The experimental setup consisted of a single-phase transformer $(10 \mathrm{kVA}, 0-2.5 \mathrm{kA}, 50 \mathrm{~Hz})$ connected to the outer loop which included the connectors described above. A calibrated Rogowski coil probe (Fluke i6000s Flex) was used to measure 
the output current provided by the transformer. To measure the temperature in steady state condition, sixteen K-type thermocouples with an AISI 316 external sheath of $1 \mathrm{~mm}$ diameter were placed on the terminal's barrel and on the top points of each conductor. An extra K-type thermocouple was used to measure the room temperature.

\section{Simulation and experimental results}

\subsection{Model I: Temperature rise test according to the ANSI/NEMA CC1-2009 standard}

When performing standard temperature rise tests, the rated current must be in accordance with the values suggested by the ANSI/NEMA CC1-2009, which depend on the conductor size. Since the analyzed connector is joined to two ACSS LARK conductors $(d=20.5 \mathrm{~mm})$, the rated testing current must be 986 $\mathrm{A}_{\mathrm{rms}}$.

Fig. 5a shows the temperature evolution of the convective coefficient $h$ of the connector and the conductor in Model I, whereas Fig. 5b shows the time evolution of $h$ because of the time-dependence of temperature.
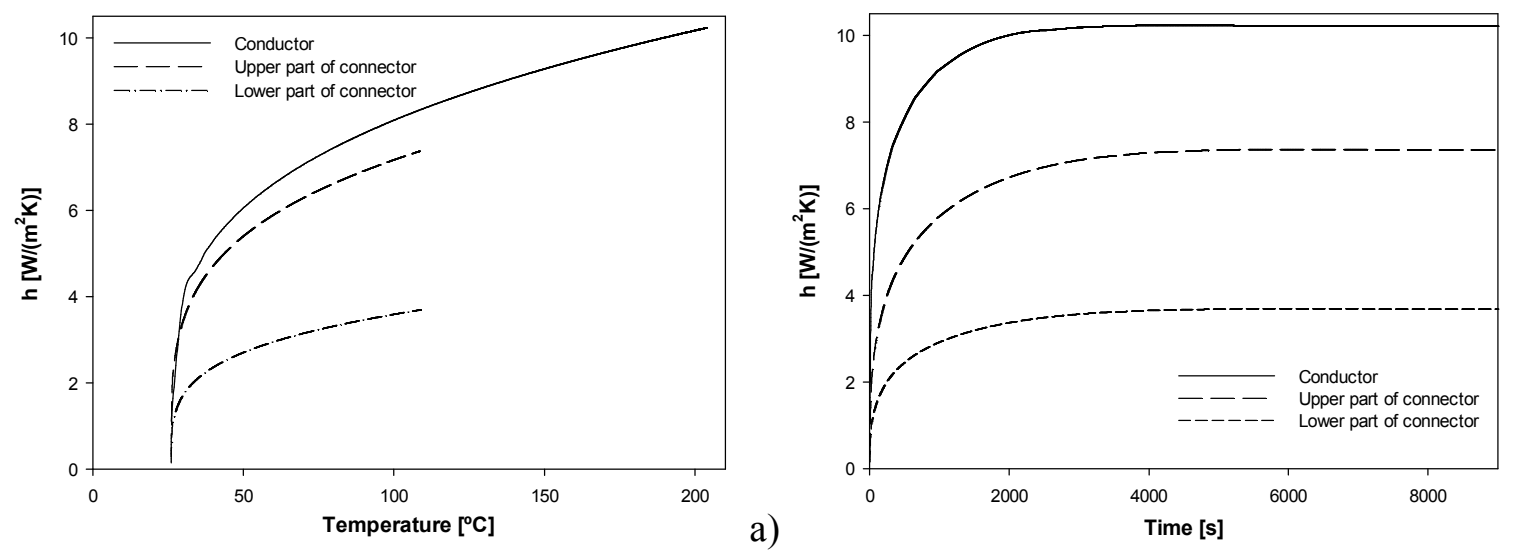

b)

Fig. 5. Model I. Evolution of the convective coefficients $h$ a) with temperature and b) with time.

Figs. $6 \mathrm{a}$ and $6 \mathrm{~b}$ show the temperature distribution under steady-state condition $(t=9000 \mathrm{~s})$ on the conductors' and connector's surfaces. Fig. 6c compares simulation and experimental temperature-rise test results, for both the ACSS conductor and a point of the T-connector (cap 3). 

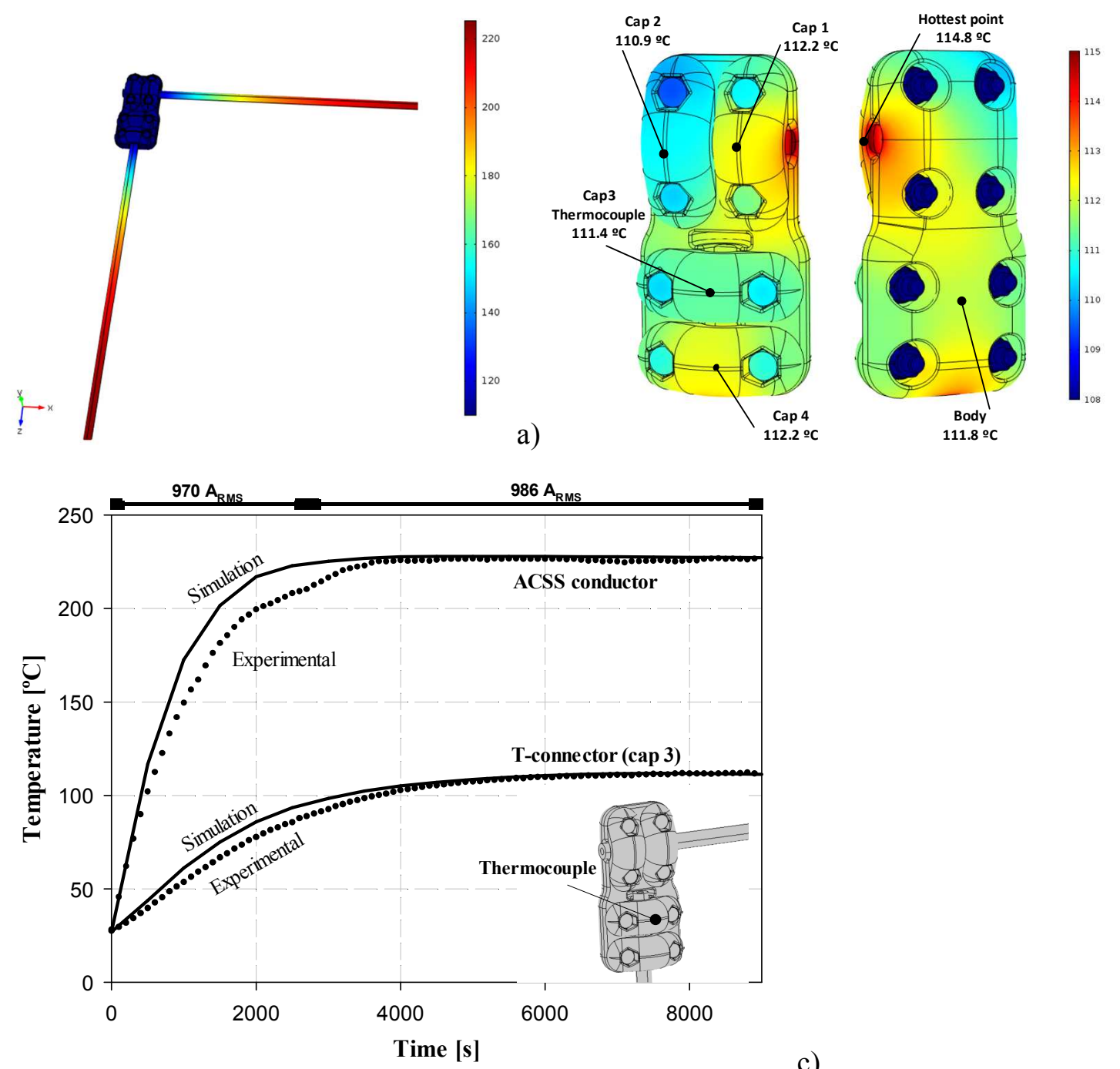

c)

Fig. 6. Model I. Three-dimensional plot of the simulated temperature distribution $\left({ }^{\circ} \mathrm{C}\right)$ under steady-state conditions $(t=$ 9000 s) when circulating a total current of $986 A_{r m s}$. a) Conductors and T-connector. b) T-connector. c) Temperature rise test according to ANSI NEMA CC1.T-connector (cap 3). Experimental versus FEM simulation results when circulating a current of $986 A_{R M S}$.

As shown in Fig. 6c, the temperature distribution in conductors and connectors in both transient and steady state conditions provided by the proposed simulation method shows good agreement with experimental data. It should be pointed out that the difference between experimental and simulation results during the transient part of the temperature rise test is because the simulation assumes a constant current of $986 \mathrm{~A}_{\mathrm{RMS}}$ whereas the current delivered by the power transformer was not stable during the transient part as indicated in Fig. 6c. 
Table 5 compares measured and simulated steady state temperatures for the connector and the conductors in Model I.

Table 5 Steady state temperature for Model I. Experimental versus FEM simulation results.

\begin{tabular}{llll}
\hline Part $^{1}$ & $\begin{array}{l}\text { T measured } \\
\left({ }^{\circ} \mathbf{C}\right)\end{array}$ & $\begin{array}{l}\text { T simulated } \\
\left({ }^{\circ} \mathbf{C}\right)\end{array}$ & $\begin{array}{l}\text { Difference } \\
(\%)\end{array}$ \\
\hline Conductor 1 & 226.6 & 227.5 & $0.4 \%$ \\
Conductor 2 & 226.8 & 227.6 & $0.3 \%$ \\
Cap 1 & 112.2 & 112.2 & $<0.1 \%$ \\
Cap 2 & 107.5 & 110.9 & $3.1 \%$ \\
Cap 3 & 112.0 & 111.4 & $0.5 \%$ \\
Cap 4 & 115.2 & 112.2 & $2.6 \%$ \\
Body & 111.5 & 111.8 & $0.3 \%$ \\
\hline
\end{tabular}

${ }^{\mathrm{I}}$ See Fig. 6b

Results presented in Table 5 show that differences between experimental and simulation results are below $3.1 \%$ in all simulated points of the geometry.

\subsection{Model II: Current cycle test according to the ANSI C119.4 standard}

A second conductor-connector loop was tested in order to validate the accuracy and performance of the proposed simulation system.

According to the ANSI C119.4 standard, which regulates thermal cycling tests for low-voltage connectors, this test current must be adjusted to obtain a steady-state temperature increase on the control conductor surface of $100-105^{\circ} \mathrm{C}$ with respect to the ambient temperature [36]. For the conductor-connector dealt with in Model II, the steady- state condition is attained when applying a current of $517 \mathrm{~A}_{\text {rms. }}$. However, to accelerate the transient conditions, the current applied during the initial transient phase (first $1000 \mathrm{~s}$ ) was set to $587 \mathrm{~A}_{\mathrm{rms}}$.

Figs. 7 show the temperature and time evolution of the convective coefficient $h$ of the connector and the conductor in Model II. 

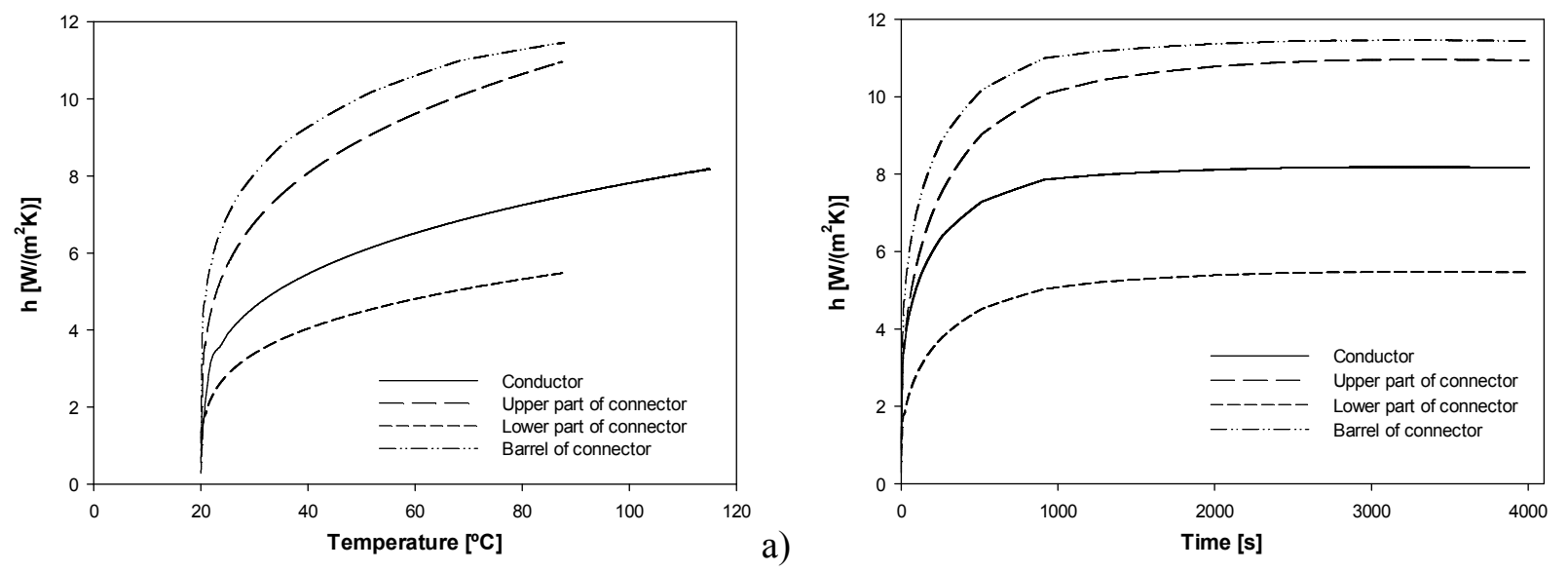

b)

Fig. 7 Model I. Evolution of the convective coefficients $h$ a) with temperature and b) with time.

Figs. $8 \mathrm{a}$ and $8 \mathrm{~b}$ show the temperature distribution at the conductors' and connector's surfaces obtained from FEM simulations. Fig. 8c compares simulation results and experimental temperature rise test results for both the AAAC conductor and connector (cap 3).
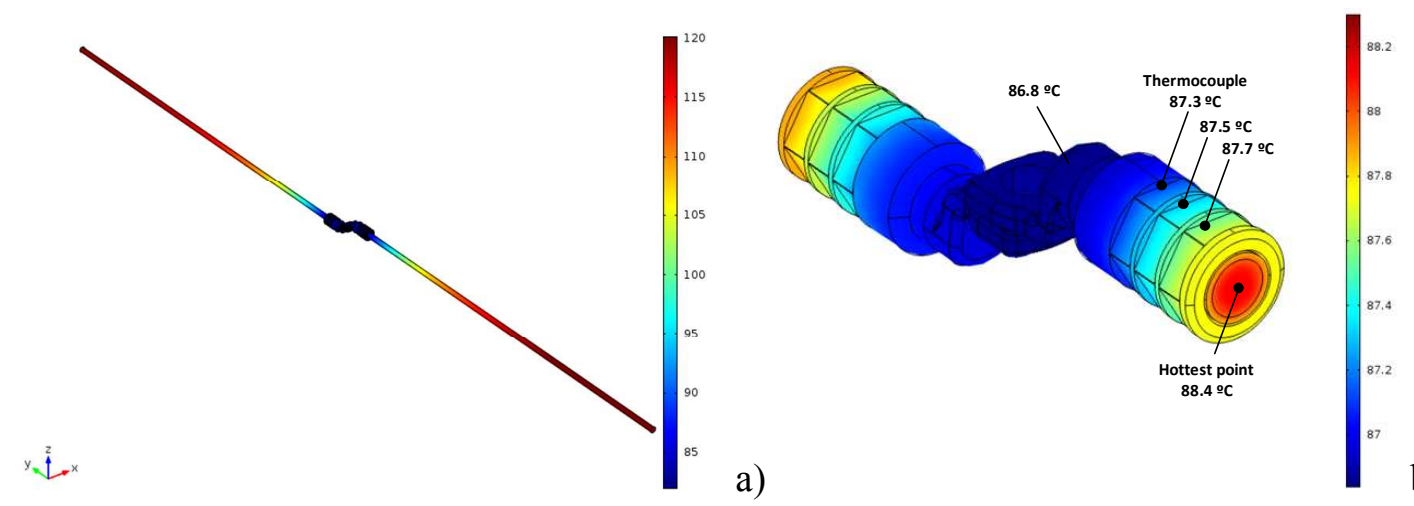

b) 


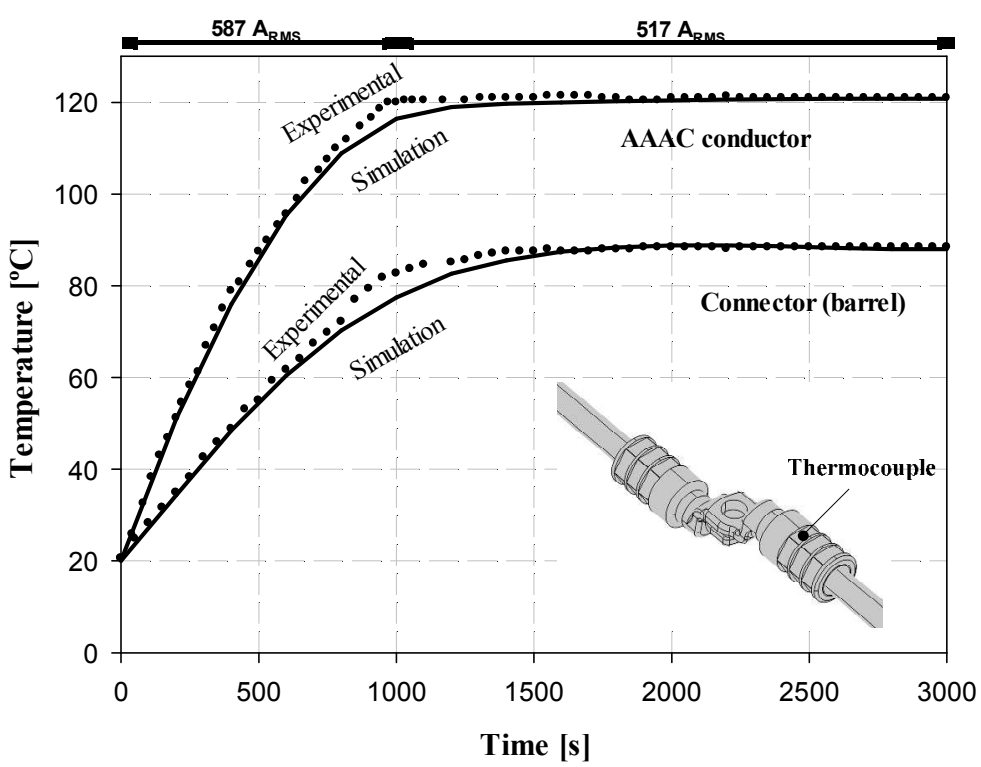

c)

Fig. 8. Model II. Three-dimensional plot of the simulated temperature distribution $\left({ }^{\circ} \mathrm{C}\right)$ under steady-state conditions $(t$ $=3000 \mathrm{~s}$ ) when circulating a current of $517 A_{\text {rms }}$. a) Conductors and bimetallic connector. b) Bimetallic connector. c) Thermal cycling test according to ANSI C119.4.Bimetallic connector $n^{\circ} 4$ (barrel). Experimental versus FEM simulation results when circulating a current of $517 A_{r m s}$.

Measured and simulated steady state temperature values are compared in Table 6.

Table 6 Steady state temperature for Model II. Experimental versus FEM simulation results.

\begin{tabular}{llll}
\hline \multicolumn{1}{c}{ Part } & T measured $\left({ }^{\circ} \mathbf{C}\right)$ & T simulated $\left({ }^{\circ} \mathbf{C}\right)$ & Difference $(\%)$ \\
\hline Conductor 1 & 120.8 & 120.76 & $<0.1 \%$ \\
Barrel 1 & 88.4 & 87.3 & $1.5 \%$ \\
\hline
\end{tabular}

Results from Table 6 show that differences between experimental and simulation results are lower than $1.5 \%$ for both conductor's and connector's temperatures. Thus, the experimental results validated the feasibility and accuracy of the simulation method.

A variable time-step solver has been used to solve the problem to increase computation speed. It is noted that the elapsed time required to run a complete simulation is about 90 minutes for the T-connector S210ZTLS and about 30 minutes for the bimetallic connector ICAUL185 using an Intel Xeon CPU E52626 processor with 32 GB of RAM memory. 


\section{Conclusion}

Temperature rise tests are time consuming, require the use of high-power-test-laboratory facilities, which are very expensive and consume large amounts of power. Therefore, it is crucial to dispose of a reliable tool for predicting temperature rise tests results for substation connectors, especially during their design and improvement stages. In this paper a transient numerical-FEM approach to simulate the temperature rise in high-capacity substation connectors has been presented, which shows accurate solution and allows avoiding the realization of preliminary factory tests, thus saving energy-related costs and time involved in planning and performing such tests. The realistic multiphysics method proposed in this paper allows satisfying the electrical and thermal requirements imposed by the compulsory standard tests, thus ensuring an adequate electromagnetic and thermal behavior of the connectors under study. This method is also applicable to other connector types and power devices. Experimental results have validated the feasibility and usefulness of the proposed methodology, which may be a valuable tool to assist the design process of substation connectors including those compatible with the HTLS technology.

\section{Acknowledgments}

The authors would like to thank SBI-Connectors Spain that supported this study by provisioning the samples and the equipment required for the experimental tests. They also thank the Spanish Ministry of Economy and Competitiveness and Generalitat de Catalunya for the financial support received under projects RTC-2014-2862-3 and DI-2013-024, respectively

\section{References}

1 CIGRE: 'Coping with Limits for Very High Penetrations of Renewable Energy - Adaptation aux limites atteintes avec des pénétrations très importantes d'énergies renouvelables' (2013), pp. 74-79

2 da Silva, A.A.P., de Barros Bezerra, J.M.: 'A Model for Uprating Transmission Lines by Using HTLS Conductors' (2011), 26, pp. 2180-2188

3 Gomez Exposito, A., Santos, J.R., Romero, P.C.: 'Planning and Operational Issues Arising From the Widespread Use of HTLS Conductors' (2007), 22, pp. 1446-1455

4 'ANSI/NEMA CC1. Electric Power Connection for Substation.' (Rosslyn, 2009)

5 Wang, J.J.-A.J.J.-A., Chan, J.K., Graziano, J.A.: 'The Lifetime Estimate for ACSR Single-Stage Splice Connector Operating at Higher Temperatures'IEEE Trans. Power Deliv., 2011, 26, (3), pp. 
$1317-1325$.

Hernández-Guiteras, J., Riba, J.-R., Romeral, L.: 'Improved design of an extra-high-voltage expansion substation connector through magnetic field analysis'Simul. Model. Pract. Theory, 2014, 43, pp. 96-105.

7 Takahashi, T., Ito, T., Okamoto, T., Imajo, T.: 'Development of calculation system for transient temperature rise of power cables in protection pipe', in 'IEEE/PES Transmission and Distribution Conference and Exhibition’ (IEEE, 2002), pp. 1899-1904

8 Li, Y., Liang, Y., Li, Y., Si, W., Yuan, P., Li, J.: 'Coupled Electromagnetic-Thermal Modeling the Temperature Distribution of XLPE Cable', in '2009 Asia-Pacific Power and Energy Engineering Conference' (IEEE, 2009), pp. 1-4

9 Jeong-Hoon Yoon, Heui-Sub Ahn, Jongung Choi, Il-Sung Oh: 'An Estimation Technology of Temperature Rise in GIS Bus Bar using Three-Dimensional Coupled-Field Multiphysics’, in 'Conference Record of the 2008 IEEE International Symposium on Electrical Insulation' (IEEE, 2008), pp. 432-436

10 Hameyer, K., Driesen, J., De Gersem, H., Belmans, R.: 'The classification of coupled field problems'IEEE Trans. Magn., 1999, 35, (3), pp. 1618-1621.

11 Buonanno, G.: 'Effect of radiative and convective heat transfer on thermal transients in power cables'IEE Proc. - Gener. Transm. Distrib., 1995, 142, (4), p. 436.

12 Kim, S.W., Kim, H.H., Hahn, S.C., et al.: 'Coupled finite-element-analytic technique for prediction of temperature rise in power apparatus'IEEE Trans. Magn., 2002, 38, (2), pp. 921-924.

13 Paisios, M.P., Karagiannopoulos, C.G., Bourkas, P.D.: 'Estimation of the temperature rise in cylindrical conductors subjected to heavy 10/350 $\mu$ s lightning current impulses'Electr. Power Syst. Res., 2008, 78, (1), pp. 80-87.

14 Terracciano, M., Purushothaman, S., de León, F.: 'Calculation of cable thermal rating considering non-isothermal earth surface'IET Gener. Transm. Distrib., 2014, 8, (7), pp. 1354-1361.

15 Holyk, C., Liess, H.-D., Grondel, S., Kanbach, H., Loos, F.: 'Simulation and measurement of the steady-state temperature in multi-core cables'Electr. Power Syst. Res., 2014, 116, pp. 54-66. Soulinaris, G.K., Halevidis, C.D., Polykrati, A.D., Bourkas, P.D.: 'Evaluation of the thermal stresses and dielectric phenomena in the investigation of the causes of wildfires involving distribution power lines'Electr. Power Syst. Res., 2014, 117, pp. 76-83. 'COMSOL 4.3 Multiphysics User's Guide' (2012)

18 Kasap, S.O.: 'Principles of Electronic Materials and Devices' (McGraw-Hill, 2006) 
'IEC 60287-1-1. Electric cables - Calculation of current rating - Part 1: Current rating equations (100\% load factor) and calculation of losses' (2006)

20 Capelli, F., Riba, J.-R., Rodriguez, A., Lalaouna, S.: 'Research Towards Energy-Efficient Substation Connectors', in '3rd International Congress on Energy Efficiency and Energy Related Materials (ENEFM2015)' (Springer, 2016)

21 Özişik, M.N.: 'Heat Transfer: A Basic Approach' (McGraw-Hill, 1985)

22 Fernandez, E., Torres, E., Zamora, I., Mazon, A.J., Albizu, I.: 'Thermal model for current limiting fuses installed in vertical position'Electr. Power Syst. Res., 2014, 107, pp. 167-174.

23 'IEEE Standard for Calculating the Current-Temperature of Bare Overhead Conductors' (2007), pp. c1-59

24 Kakaç, S., Yener, Y.: 'Convective Heat Transfer, Second Edition’ (CRC Press, 1994)

25 Buckingham, E.: 'On Physically Similar Systems; Illustrations of the Use of Dimensional Equations'Phys. Rev., 1914, 4, (4), pp. 345-376.

26 Bejan, A.: 'Convection Heat Transfer' (John Wiley \& Sons, 2013)

27 Lienhard, J.H.: ‘A Heat Transfer Textbook: Fourth Edition’ (Courier Corporation, 2013)

28 Churchill, S.W., Chu, H.H.S.: 'Correlating equations for laminar and turbulent free convection from a horizontal cylinder'Int. J. Heat Mass Transf., 1975, 18, (9), pp. 1049-1053.

29 McAdams, W.H.: 'Heat Transmission' (1954)

30 Pilgrim, J.A., Lewin, P., Huang, Z., Swingler, S., Tzemis, G.: 'Thermal modelling and analysis for offshore submarine high-voltage direct current cable crossings'IET Gener. Transm. Distrib., 2015, 9, (16), pp. 2717-2723.

31 Taylor, C.S., House, H.E.: 'Emissivity and Its Effect on the Current-Carrying Capacity of Stranded Aluminum Conductors [includes discussion]'Trans. Am. Inst. Electr. Eng. Part III Power Appar. Syst., 1956, 75, (3).

32 General Cable: 'TransPowr ${ }^{\circledR}$ ACSS Bare Overhead Conductor - Aluminum Conductor SteelSupported Concentric-Lay-Stranded' (no date)

33 'ASM Ready Reference: Thermal properties of metals' (ASM International, 2002)

34 Öhman, C.: 'Emittansmätningar med AGEMA E-Box. Teknisk rapport, AGEMA' (1999)

35 Flir: 'Flir i3 user's manual, FLIR Systems' (Flir, 2011), p. 178

36 'ANSI C119.4 Connectors for use between aluminum to aluminum and aluminum to cooper conductors designed for normal operation at or below 93 degree $\mathrm{C}$ and copper to copper conductors designed for normal operation at or below 100. degree C.' (2011) 